\title{
CyberKnife for hilar lung tumors: report of clinical response and toxicity
}

\author{
Keith Unger ${ }^{*}$, Andrew Ju1 , Eric Oermann ${ }^{1}$, Simeng Suy ${ }^{1}, \mathrm{Xia}_{\mathrm{Yu}}{ }^{1}$, Saloomeh Vahdat ${ }^{4}$, Deepa Subramaniam², \\ K William Harter ${ }^{1}$, Sean P Collins ${ }^{1}$, Anatoly Dritschilo ${ }^{1}$, Eric Anderson ${ }^{3}$, Brian T Collins ${ }^{1}$
}

\begin{abstract}
Objective: To report clinical efficacy and toxicity of fractionated CyberKnife radiosurgery for the treatment of hilar lung tumors.

Methods: Patients presenting with primary and metastatic hilar lung tumors, treated using the CyberKnife system with Synchrony fiducial tracking technology, were retrospectively reviewed. Hilar location was defined as abutting or invading a mainstem bronchus. Fiducial markers were implanted by conventional bronchoscopy within or adjacent to tumors to serve as targeting references. A prescribed dose of 30 to 40 Gy to the gross tumor volume (GTV) was delivered in 5 fractions. Clinical examination and PET/CT imaging were performed at 3 to 6 -month follow-up intervals.
\end{abstract}

Results: Twenty patients were accrued over a 4 year period. Three had primary hilar lung tumors and 17 had hilar lung metastases. The median GTV was $73 \mathrm{cc}$ (range 23-324 cc). The median dose to the GTV was 35 Gy (range, 30 - $40 \mathrm{~Gy}$ ), delivered in 5 fractions over 5 to 8 days (median, 6 days). The resulting mean maximum point doses delivered to the esophagus and mainstem bronchus were 25 Gy (range, 11 - 39 Gy) and 42 Gy (range, 30 - 49 Gy), respectively. Of the 17 evaluable patients with $3-6$ month follow-up, 4 patients had a partial response and 13 patients had stable disease. AAT t a median follow-up of 10 months, the 1-year Kaplan-Meier local control and overall survival estimates were $63 \%$ and $54 \%$, respectively. Toxicities included one patient experiencing grade II radiation esophagitis and one patient experiencing grade III radiation pneumonitis. One patient with gross endobronchial tumor within the mainstem bronchus developed a bronchial fistula and died after receiving a maximum bronchus dose of $49 \mathrm{~Gy}$.

Conclusion: Cyberknife radiosurgery is an effective palliative treatment option for hilar lung tumors, but local control is poor at one year. Maximum point doses to critical structures may be used as a guide for limiting toxicities. Preliminary results suggest that dose escalation alone is unlikely to enhance the therapeutic ratio of hilar lung tumors and novel approaches, such as further defining the patient population or employing the use of radiation sensitizers, should be investigated.

\section{Introduction}

Patients presenting with inoperable lung tumors are generally treated with conventionally fractionated radiotherapy. To improve local control and survival, researchers in the past decade have explored various means of delivering high doses of radiation in shorter intervals [1]. Lung tumors have been treated with relatively tight margins $(10 \mathrm{~mm})$ utilizing a body frame and abdominal

\footnotetext{
*Correspondence: kxu2@georgetown.edu

'Department of Radiation Medicine, Georgetown University Hospital, Washington, DC, USA

Full list of author information is available at the end of the article
}

compression to restrict lung motion [2]. This enhanced precision has facilitated the safe delivery of highly effective hypofractionated doses of radiation quickly to peripheral lung tumors [3-16]. However, for central lung tumors, treatment related deaths have been attributed to radiation induced bronchial and esophageal injury $[5,13]$. An ongoing Radiation Therapy Oncology Group (RTOG) protocol is exploring potentially safer 5 fraction treatment regimens for small $(<5 \mathrm{~cm})$ centrally located non-small cell lung cancers (NSCLCs) [17].

The CyberKnife System (Accuray Incorporated, Sunnyvale, CA) has been successfully employed at Georgetown 
University Hospital since early 2002 to treat stationary extracranial tumors [18]. With the introduction of the Synchrony ${ }^{\text {Ta }}$ motion tracking module in 2004, small peripheral and perihilar lung tumors that move with respiration have been successfully treated using tighter margins than previously feasible $[19,20]$. Here we report clinical results from 20 consecutive patients with hilar lung tumors abutting or invading the mainstem bronchus, treated in 5 fractions using the CyberKnife System with Synchrony ${ }^{\mathrm{max}}$.

\section{Methods and Materials Eligibility}

This retrospective review of an established departmental treatment policy was approved by the Georgetown University institutional review board. Consecutively treated patients between October 2005 and October 2009 with pathologically confirmed inoperable primary hilar lung cancers or hilar lung metastases were reviewed. A tumor was considered a "hilar lung tumor" if it abutted or invaded the mainstem bronchus. Baseline studies included PET/CT imaging with iodinated IV contrast as clinically feasible.

\section{Fiducial Placement}

Tracking based on translational and rotational target information requires the use of a minimum of 3 noncollinear fiducials to be visible on the orthogonal images of the CyberKnife $\mathrm{x}$-ray targeting system. Three to five gold fiducials measuring $0.8-1 \mathrm{~mm}$ in diameter by 3-7 $\mathrm{mm}$ in length (Item 351-1 Best Medical International, Inc., Springfield, VA) were placed in or near the tumors via bronchoscopy as previously described [21].

\section{Treatment Planning}

Fine-cut $(1.25 \mathrm{~mm})$ treatment planning CT's were obtained following fiducial placement during a full inhalation breath hold with the patient in the supine treatment position. Gross tumor volumes (GTV) were contoured utilizing mediastinal windows. A treatment plan was generated using the TPS 5.2.1 non-isocentric, inverse-planning algorithm with tissue density heterogeneity corrections for lung based on an effective depth correction. The radiation dose was divided into 5 equal fractions of 6 to $8 \mathrm{~Gy}$, prescribed to an isodose line that covered at least $95 \%$ of the planning treatment volume (PTV $=$ GTV). Guidelines for dose limits to critical central thoracic structures are provided in Table 1. In general, prescribed doses were increased with clinical experience.

\section{Treatment Delivery}

Patients were treated in the supine position with their arms at their sides. A form-fitting vest containing 3 red light-emitting surface markers was attached to the
Table 1 Radiation maximum point dose limits

\begin{tabular}{lc}
\hline $\begin{array}{l}\text { Adjacent } \\
\text { Structure }\end{array}$ & $\begin{array}{c}\text { Maximum Point Dose Limit (Gy) (total for } \mathbf{5} \\
\text { fractions) }\end{array}$ \\
\hline Spinal cord & 25 \\
\hline Left ventricle & 30 \\
\hline Esophagus & 40 \\
\hline Major bronchus & 50 \\
\hline
\end{tabular}

surface of the patient's anterior torso in the region of maximum chest and upper abdominal respiratory excursion. These markers projected to an adjustable camera array in the treatment room. Precise patient positioning was accomplished utilizing the automated patient positioning system. The internal fiducials were located using orthogonal $x$-ray images acquired with ceiling-mounted diagnostic $x$-ray sources and corresponding amorphous silicon image detectors secured to the floor on either side of the patient.

Prior to initiating treatment, an adaptive correlation model was created between the fiducial positions as periodically imaged by the $\mathrm{x}$-ray targeting system and the light-emitting markers as continuously imaged by the camera array. During treatment delivery the tumor position was tracked using the live camera array signal and correlation model, and the linear accelerator was moved by the robotic arm in real time to maintain alignment with the tumor. Fiducials were imaged prior to the delivery of every third beam for treatment verification and to update the correlation model.

\section{Follow-up Studies}

Patients were followed with physical examination and $\mathrm{PET} / \mathrm{CT}$ imaging at 3 to 6 month intervals. Local tumor recurrence was defined as progression of the treated tumor on PET/CT imaging. Biopsies were obtained when clinically indicated. Early treatment response was defined by the Response Evaluation Criteria in Solid Tumors (RECIST) Committee [22]. Toxicities were scored according to the National Cancer Institute Common Terminology Criteria for Adverse Events, Version 3.0 [23].

\section{Statistical Analysis}

Statistical analysis was performed with the MedCalc 11.1 statistical package. The follow-up duration was defined as the time from the date of completion of treatment to the last date of follow-up or the date of death. Actuarial local control and overall survival were calculated using the Kaplan-Meier method.

\section{Results}

\section{Patient and Tumor Characteristics}

Twenty consecutive patients ( 10 men and 10 women) were treated over a 4-year period (Table 2). Three 
Table 2 Patient and Tumor Characteristics

\begin{tabular}{|c|c|c|c|c|c|c|c|c|}
\hline Patient & Age & Sex & Performance Status (ECOG) & Symptom & Category & Histology & GTV (cc) & Mainstem Endobronchial Tumor \\
\hline 1 & 62 & M & 2 & Cough & Metastasis & NSCLC & 152 & No \\
\hline 2 & 67 & $\mathrm{~F}$ & 0 & SOB & Metastasis & Sarcoma & 179 & No \\
\hline 3 & 79 & M & 2 & SOB & Primary & NSCLC & 137 & No \\
\hline 4 & 71 & $\mathrm{~F}$ & 2 & Cough & Primary & NSCLC & 221 & No \\
\hline 5 & 65 & $\mathrm{~F}$ & 2 & SOB & Primary & NSCLC & 68 & No \\
\hline 6 & 13 & M & 0 & None & Metastasis & Sarcoma & 44 & No \\
\hline 7 & 76 & $\mathrm{~F}$ & 1 & Cough & Metastasis & $\mathrm{NSCLC}$ & 41 & Yes \\
\hline 8 & 69 & M & 2 & Pain & Metastasis & NSCLC & 68 & No \\
\hline 9 & 61 & $\mathrm{~F}$ & 0 & SOB & Metastasis & Renal & 182 & No \\
\hline 10 & 59 & M & 0 & None & Metastasis & NSCLC & 38 & No \\
\hline 11 & 65 & M & 1 & SOB & Metastasis & Mesothelioma & 324 & Yes \\
\hline 12 & 23 & $\mathrm{~F}$ & 0 & None & Metastasis & Colon & 39 & No \\
\hline 13 & 49 & $M$ & 0 & Cough & Metastasis & Renal & 58 & No \\
\hline 14 & 46 & M & 0 & $\mathrm{SOB}$ & Metastasis & Colon & 141 & No \\
\hline 15 & 81 & $\mathrm{~F}$ & 1 & Cough & Metastasis & NSCLC & 50 & No \\
\hline 16 & 71 & M & 1 & $\mathrm{SOB}$ & Metastasis & NSCLC & 78 & No \\
\hline 17 & 82 & $\mathrm{~F}$ & 0 & None & Metastasis & NSCLC & 23 & No \\
\hline 18 & 51 & $\mathrm{~F}$ & 0 & SOB & Metastasis & Breast & 64 & No \\
\hline 19 & 58 & $F$ & 0 & Cough & Metastasis & Salivary Gland & 87 & No \\
\hline 20 & 62 & $M$ & 0 & SOB & Metastasis & Renal & 111 & Yes \\
\hline
\end{tabular}

patients presented with primary lung tumors (adenocarcinoma 1, squamous cell carcinoma 2) and 17 with hilar lung metastases (NSCLC 7, renal cell carcinoma 3, sarcoma 2, colon cancer 2 , breast cancer 1 , mesothelioma 1 and adenoid cystic cancer 1 ). The patients with primary lung cancer were treated with radiosurgery due to severe pulmonary dysfunction. The mean gross tumor volume (GTV) was $73 \mathrm{cc}$ (range, 23 - $324 \mathrm{cc}$ ). Bronchoscopy for fiducial placement documented gross mainstem endobronchial tumor in 3 patients.

\section{Treatment Characteristics}

Treatment plans were composed of hundreds of pencil beams delivered using a single 20 to $40-\mathrm{mm}$ diameter collimator (median, $30 \mathrm{~mm}$ ). Radiation was delivered in 5 equal fractions of 6 to 8 Gy each to a median prescription isodose line of $76 \%$ (range, $70-80 \%$ ). The median dose delivered to the prescription isodose line over an average of 6 days (range, 5-8) was 35 Gy (range, 3040 Gy). The resulting mean maximum point doses delivered to the esophagus and mainstem bronchus were 25 Gy (range, 11 - 39 Gy) and 42 Gy (range, 30 - 49 Gy), respectively.

\section{Early Clinical and Radiographic Response}

All patients underwent clinical follow-up, and 14 patients reported symptomatic relief within 1 month of treatment and 2 patients reported relief by 4 months. Of the 17 patients with early radiographic follow-up, 4 patients experienced partial responses and 13 patients had stable disease at $3-6$ months. There was no local disease progression within the 6-month follow-up interval. Furthermore, 13 patients with serial PET/CT imaging exhibited early declines in the maximum standardized uptake values (Figure 1).

\section{Local Control and Survival}

Despite excellent early clinical and radiographic responses, local control and survival outcomes beyond 6 months were poor. At a median follow-up of 10 months, the 1-year Kaplan-Meier local control and overall survival estimates were only $63 \%$ and $54 \%$, respectively (Figure 2,3$)$. Deaths were largely attributed to metastatic disease (Table 3). However, despite limited follow-up and poor survival, 6 local failures were documented. One such failure resulted in a patient's death (Figure 4).

\section{Complications}

Strict maximum point dose constraints were maintained for normal tissues. Immediately following treatment, mild brief fatigue was reported by the majority of patients. Acute Grade II esophagitis, requiring brief hospitalization for IV hydration, was observed in 1 patient with renal cell carcinoma presenting with a relatively large GTV $\left(182 \mathrm{~cm}^{3}\right)$ and a high maximum esophageal point dose approaching the limit of $40 \mathrm{~Gy}$. A second 


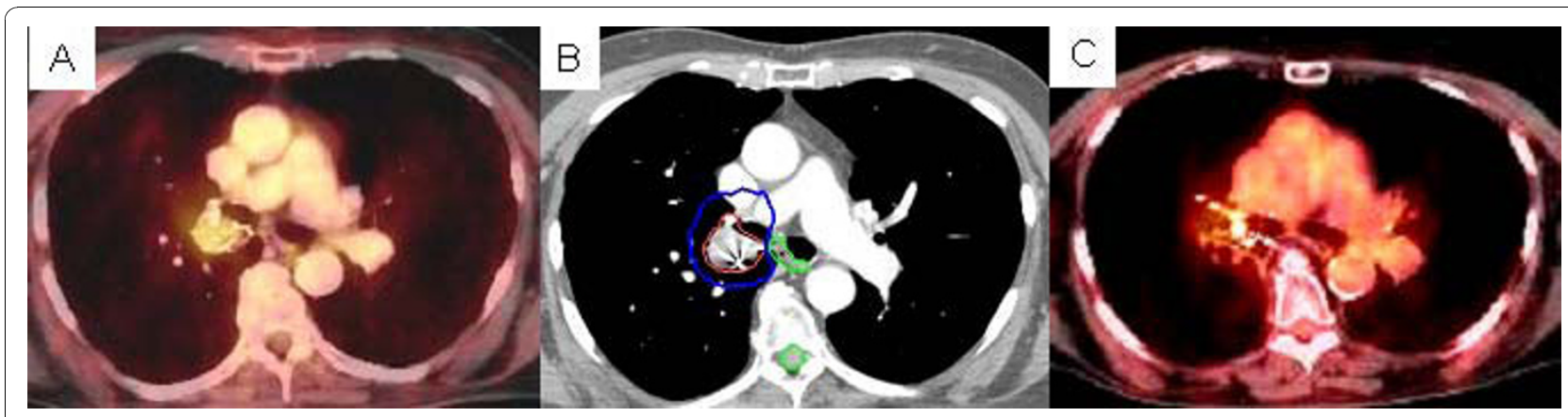

Figure 1 Right hilar metastasis treatment planning PET/CT with a tumor SUV max $_{\text {of }} 9.6$ (A), planned radiation dose distribution (B: the planning treatment volume is shown in red and the $35 \mathrm{~Gy}$ isodose line in blue), and PET/CT at 6 months post-treatment (C) shows an excellent response with a tumor $\mathrm{SUV}_{\max }$ of 2.7.

patient with severe COPD and progressing metastatic NSCLC developed dyspnea and an infiltrate on CT corresponding to the high dose treatment volume 8 months following CyberKnife treatment (40 Gy). He required temporary supplemental oxygen and his symptoms resolved with conservative treatment over a 4 day hospital stay. Finally, a patient with advanced mesothelioma developed a mainstem bronchus fistula 7 months following treatment and died (Figure 5). He was one of 3 patients with gross mainstem endobronchial disease. Additionally, the GTV was relatively large $\left(324 \mathrm{~cm}^{3}\right)$ and the mainstem bronchus received a maximum point dose of 49 Gy.

\section{Discussion}

Continuous tracking of respiratory tumor motion and precise beam alignment throughout treatment permits greater dose conformality to the tumor contour and a sharp dose gradient $[19,24]$. We observed prompt symptomatic relief in 16 patients, likely due to the high dose

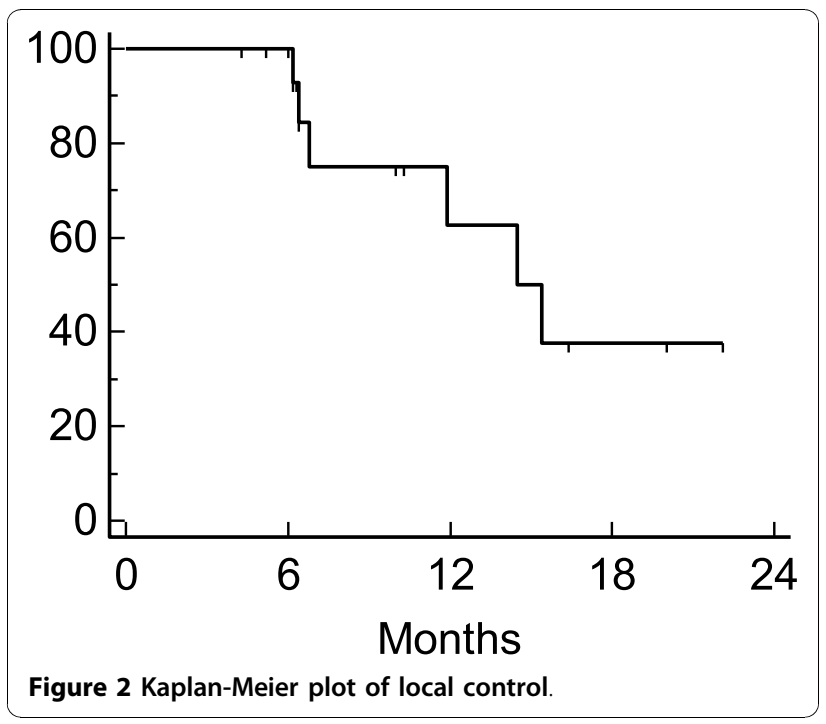

per fraction. Furthermore, within 6 months of treatment there was no evidence of local tumor progression and the local control rate at 1 year was $63 \%$. Our results compare favorably to a large RTOG trial of conventionally fractionated radiation therapy for palliation of inoperable NSCLC, which demonstrated palliation of symptoms in $60 \%$ and local control in $41 \%$ [25]. We conclude that stereotactic radiosurgery with real-time tumor motion tracking and continuous beam correction provides a well-tolerated and effective treatment option for hilar lung tumors.

Prior to proceeding with our institutional study of CyberKnife radiosurgery for hilar lung tumors, maturing data of others suggested that critical central thoracic structures tolerate high-dose hypofractionated radiation poorly [5]. In a phase II trial using 60-66 Gy in 3 fractions for the treatment of NSCLC, severe toxicity was noted in $46 \%$ of patients with central lung tumors at 2 years [5]. Therefore, we limited doses to 30-40 Gy in 5 fractions prescribed to the gross tumor volume without

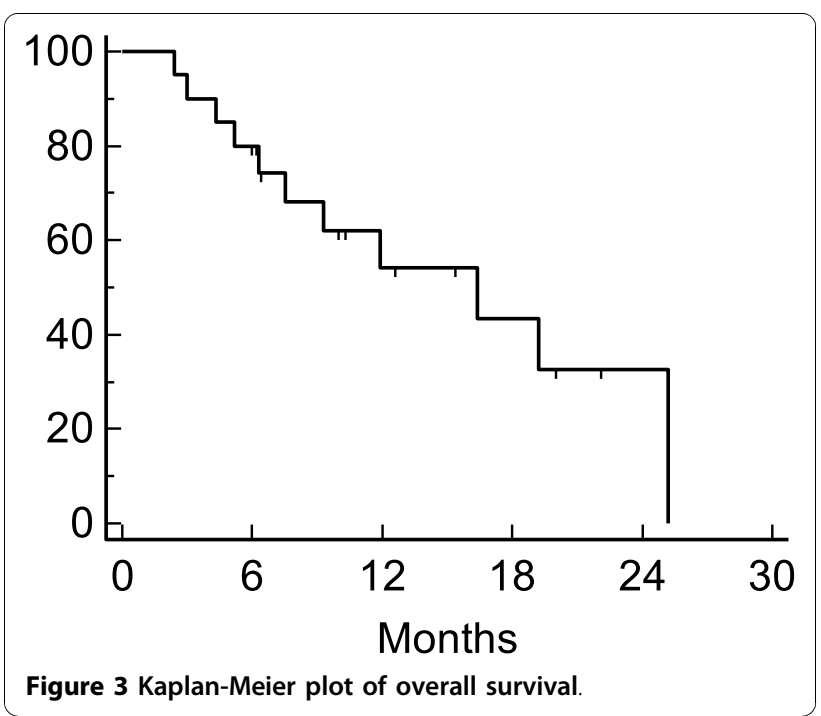


Table 3 Clinical Outcomes

\begin{tabular}{|c|c|c|c|c|}
\hline Patient & Vital Status & Survival (Months) & Local Failure (Months) & Cause of Death \\
\hline 1 & Dead & 3 & N/A & Metastases \\
\hline 2 & Dead & 4 & N/A & Metastases \\
\hline 3 & Dead & 5 & N/A & Metastases \\
\hline 4 & Dead & 6 & N/A & Pulmonary \\
\hline 5 & Dead & 12 & 8 & Metastases \\
\hline 6 & Dead & 19 & 12 & Metastases \\
\hline 7 & Dead & 25 & 14 & Metastases \\
\hline 8 & Dead & 9 & 8 & Local Failure \\
\hline 9 & Alive & N/A & N/A & N/A \\
\hline 10 & Alive & N/A & N/A & N/A \\
\hline 11 & Dead & 7 & N/A & Fistula \\
\hline 12 & Alive & N/A & N/A & N/A \\
\hline 13 & Dead & 16 & N/A & Metastases \\
\hline 14 & Alive & N/A & 15 & N/A \\
\hline 15 & Alive & N/A & 9 & N/A \\
\hline 16 & Alive & N/A & N/A & N/A \\
\hline 17 & Alive & N/A & N/A & N/A \\
\hline 18 & Alive & N/A & N/A & N/A \\
\hline 19 & Alive & N/A & N/A & N/A \\
\hline 20 & Dead & 3 & N/A & Metastases \\
\hline
\end{tabular}

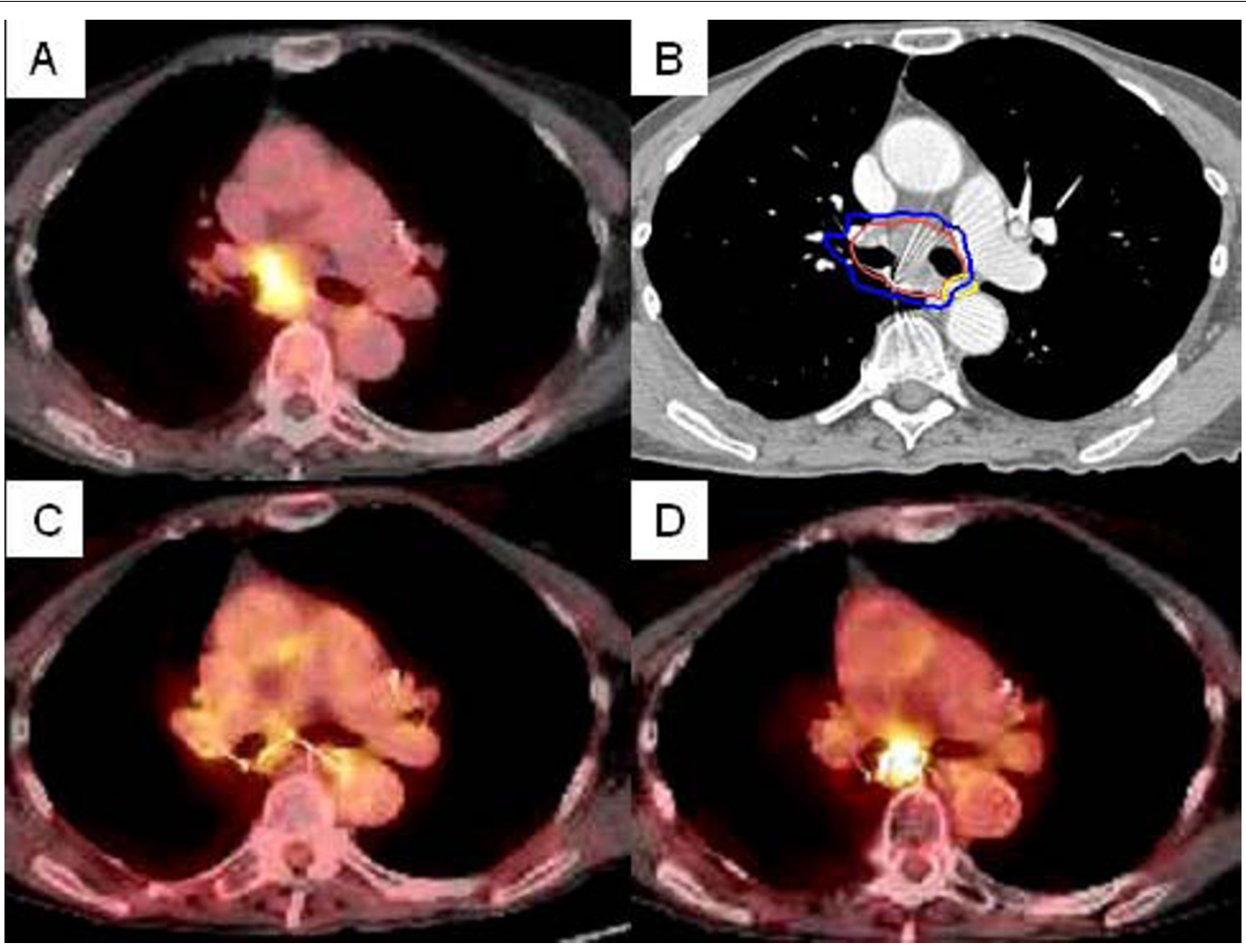

Figure 4 Right hilar tumor treatment planning PET/CT with a tumor SUV max $_{\text {of }} 7.0$ (A), planned radiation dose distribution (B: the planning treatment volume is shown in red and the $30 \mathrm{~Gy}$ isodose line in blue), and PET/CT at 6 , and 12 months post-treatment (C and D) show an initial decrease in SUV $_{\max }$ to 2.5 followed by local recurrence $\left(\mathrm{SUV}_{\max }=7.2\right)$. 


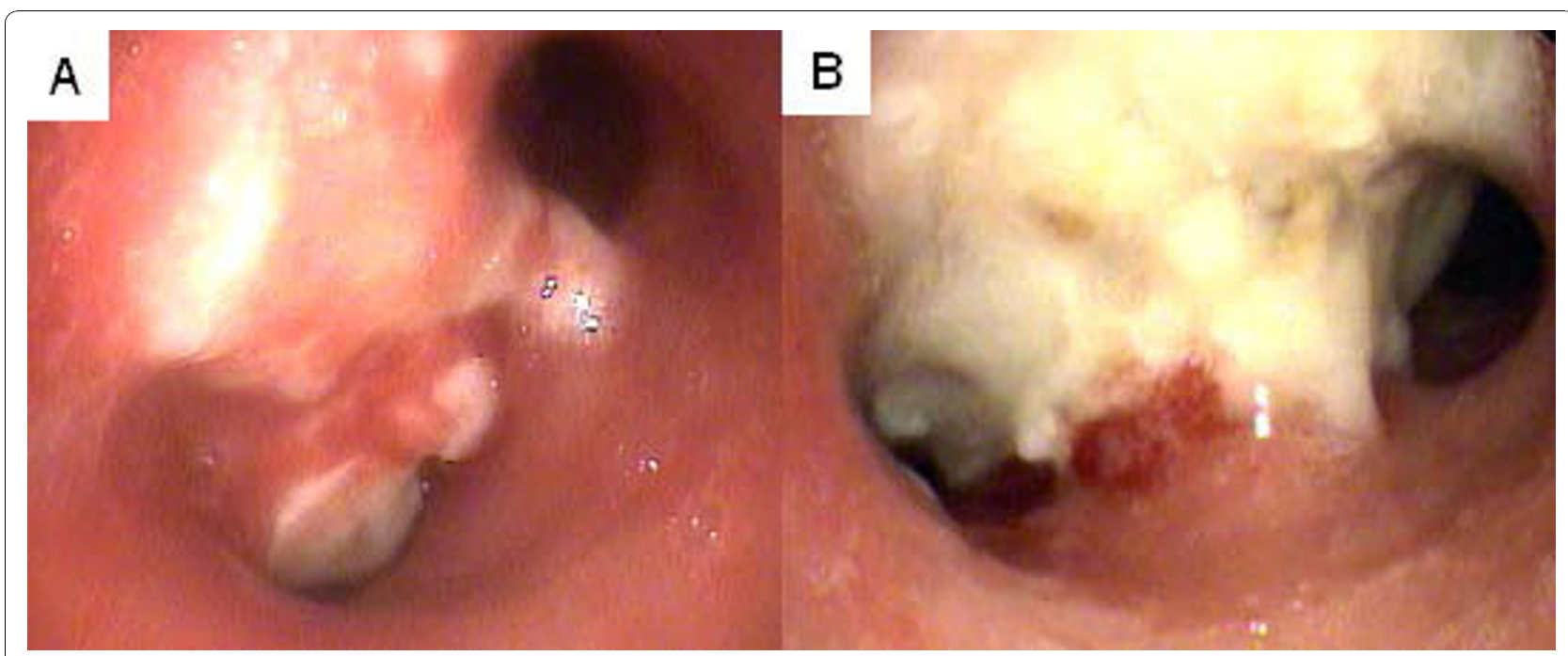

Figure 5 Mainstem gross endobronchial tumor prior to treatment (A) and biopsy proven mainstem bronchus tumor necrosis at 7 months (B).

additional margin. In the absence of validated esophagus and mainstem bronchus dose limits for stereotactic radiosurgery in 5 fractions, we limited the maximum point doses to 40 Gy and 50 Gy, respectively. Although these dose limits were not exceeded, one patient developed grade II esophagitis and a second patient developed Grade III pneumonitis. Finally, one patient with gross mainstem endobronchial disease developed a fatal airway complication after receiving a maximum point dose of 49 Gy to the mainstem bronchus. In a recently published trial, 6 patients with lung tumors directly involving major airways (i.e. main or lobar bronchi) received 40 to 48 Gy in 4 fractions [13]. As with our study, treatment related toxicity was observed, including 3 patients who developed severe pulmonary toxicity. A single patient with gross mainstem endobronchial disease, who had received 48 Gy in 4 fractions, died of complication related to radiosurgery without evidence of tumor recurrence.

Despite the short survival of treated patients and the aggressive radiation doses used, local control at 1 year was a disappointing 63\%. However, in light of dose limiting major bronchus, lung, and esophageal toxicity, further dose escalation beyond 40 Gy is not a feasible approach to improve local control in hilar tumors with a significant endobronchial component. Additional clinical trials that exclude patients with gross mainstem endobronchial disease will be necessary to define the appropriate patient characteristics and doses. Alternatively, this study provides support for investigation of novel radiation sensitizers to enhance the therapeutic ratio of hilar lung tumor radiosurgery.

\section{Conclusion}

Hilar lung tumor patients may be treated with frameless stereotactic radiosurgery, resulting in encouraging early clinical responses, acceptable acute toxicity and reliable palliation. However, local control at 1 year remains poor despite aggressive radiation doses and life threatening late toxicity has been reported, especially for tumors with a significant endobronchial component. We propose additional clinical investigation optimizing patient selection and consideration of novel combination treatments with radiation sensitizing drugs.

\section{List of Abbreviations}

CT: computed tomography; GTV: gross tumor volume; GY: Gray; NSCLC: nonsmall cell lung cancer; PET: positron emission tomography; PTV: planning treatment volume; and SUV MAX: $_{\text {maximum standardized uptake value; }}$

\section{Author details}

'Department of Radiation Medicine, Georgetown University Hospital, Washington, DC, USA. ${ }^{2}$ Division of Hematology and Oncology, Georgetown University Hospital, Washington, DC, USA. ${ }^{3}$ Division of Pulmonary, Critical Care and Sleep Medicine, Georgetown University Hospital, Washington, DC, USA. ${ }^{4}$ Department of Pathology, Georgetown University Hospital, Washington, DC, USA.

\section{Authors' contributions}

$\mathrm{KU}$ participated in data collection, data analysis and manuscript drafting and manuscript revision. AJ participated in data collection, data analysis and manuscript revision. EO participated in data collection, data analysis and manuscript revision. SS created tables and figures and participated in data analysis and manuscript revision. XY participated in treatment planning, data collection and data analysis. SV participated in data collection, data analysis and manuscript revision. DS participated in data analysis and manuscript revision. KWH participated in treatment planning, data analysis and manuscript revision. SC prepared the manuscript for submission, participated in treatment planning, data collection, data analysis and manuscript revision. AD participated in data analysis and manuscript revision. EA participated in 
treatment planning, data collection, data analysis and manuscript revision. $B C$ drafted the manuscript, participated in treatment planning, data collection and data analysis. All authors have read and approved the final manuscript.

\section{Competing interests}

$\mathrm{BC}$ is an Accuray clinical consultant. EA is paid by Accuray to give lectures.

Received: 29 May 2010 Accepted: 22 October 2010

Published: 22 October 2010

\section{References}

1. Qiao X, Tullgren O, Lax I, Sirzen F, Lewensohn R: The role of radiotherapy in treatment of stage I non-small cell lung cancer. Lung Cancer 2003, 41:1-11

2. Lax I, Panettieri V, Wennberg B, Amor Duch M, Naslund I, Baumann P, Gagliardi G: Dose distributions in SBRT of lung tumors: Comparison between two different treatment planning algorithms and Monte-Carlo simulation including breathing motions. Acta Oncol 2006, 45:978-988.

3. McGarry RC, Papiez L, Williams M, Whitford T, Timmerman RD: Stereotactic body radiation therapy of early-stage non-small-cell lung carcinoma: phase I study. Int I Radiat Oncol Biol Phys 2005, 63:1010-1015.

4. Timmerman R, Papiez L, McGarry R, Likes L, DesRosiers C, Frost S, Williams M: Extracranial stereotactic radioablation: results of a phase I study in medically inoperable stage I non-small cell lung cancer. Chest 2003, 124:1946-1955.

5. Timmerman R, McGarry R, Yiannoutsos C, Papiez L, Tudor K, DeLuca J, Ewing M, Abdulrahman R, DesRosiers C, Williams M, Fletcher J: Excessive toxicity when treating central tumors in a phase II study of stereotactic body radiation therapy for medically inoperable early-stage lung cancer. J Clin Oncol 2006, 24:4833-4839.

6. Nagata Y, Takayama K, Matsuo Y, Norihisa Y, Mizowaki T, Sakamoto T, Sakamoto M, Mitsumori M, Shibuya K, Araki N, et al: Clinical outcomes of a phase $1 / /$ study of 48 Gy of stereotactic body radiotherapy in 4 fractions for primary lung cancer using a stereotactic body frame. Int I Radiat Oncol Biol Phys 2005, 63:1427-1431.

7. Onishi H, Araki T, Shirato H, Nagata Y, Hiraoka M, Gomi K, Yamashita T, Niibe Y, Karasawa K, Hayakawa K, et al: Stereotactic hypofractionated highdose irradiation for stage I nonsmall cell lung carcinoma: clinical outcomes in 245 subjects in a Japanese multiinstitutional study. Cancer 2004, 101:1623-1631.

8. Uematsu M, Shioda A, Suda A, Fukui T, Ozeki Y, Hama Y, Wong JR, Kusano S: Computed tomography-guided frameless stereotactic radiotherapy for stage I non-small cell lung cancer: a 5-year experience. Int J Radiat Oncol Biol Phys 2001, 51:666-670.

9. Wulf J, Haedinger U, Oppitz U, Thiele W, Mueller G, Flentje M: Stereotactic radiotherapy for primary lung cancer and pulmonary metastases: a noninvasive treatment approach in medically inoperable patients. Int $J$ Radiat Oncol Biol Phys 2004, 60:186-196.

10. Hoyer M, Roed H, Hansen A, Ohlhuis L, Petersen J, Nellemann H, Berthelsen A, Grau C, Engelholm S, von der Maase H: Prospective study on stereotactic radiotherapy of limited-stage non-small-cell lung cancer. Int J Radiat Oncol Biol Phys 2006, 66:S128-S135.

11. Xia T, Li H, Sun Q, Wang Y, Fan N, Yu Y, Li P, Chang JY: Promising clinical outcome of stereotactic body radiation therapy for patients with inoperable Stage 1/II non-small-cell lung cancer. Int I Radiat Oncol Biol Phys 2006, 66:117-125

12. Nyman J, Johansson KA, Hulten U: Stereotactic hypofractionated radiotherapy for stage I non-small cell lung cancer-mature results for medically inoperable patients. Lung Cancer 2006, 51:97-103.

13. Song SY, Choi W, Shin SS, Lee SW, Ahn SD, Kim JH, Je HU, Park Cl, Lee JS, Choi EK: Fractionated stereotactic body radiation therapy for medically inoperable stage I lung cancer adjacent to central large bronchus. Lung Cancer 2009, 66:89-93.

14. Baumann P, Nyman J, Hoyer M, Wennberg B, Gagliardi G, Lax I, Drugge N, Ekberg $L$, Friesland $S$, Johansson KA, et al: Outcome in a prospective phase II trial of medically inoperable stage I non-small-cell lung cancer patients treated with stereotactic body radiotherapy. J Clin Oncol 2009, 27:3290-3296.

15. Fakiris AJ, McGarry RC, Yiannoutsos CT, Papiez L, Williams M, Henderson MA, Timmerman R: Stereotactic body radiation therapy for early-stage non-small-cell lung carcinoma: four-year results of a prospective phase II study. Int J Radiat Oncol Biol Phys 2009, 75:677-682.

16. Grills IS, Mangona VS, Welsh R, Chmielewski G, Mclnerney E, Martin S, Wloch J, Ye H, Kestin LL: Outcomes after stereotactic lung radiotherapy or wedge resection for stage I non-small-cell lung cancer. J Clin Oncol 2010, 28:928-935.

17. Seamless Phase I/II Study of Stereotactic Lung Radiotherapy (SBRT) For Early Stage, Centrally Located, Non-Small Cell Lung Cancer (NSCLC) in Medically Inoperable Patients. [http://www.rtog.org/members/protocols/ 0813/0813.pdf].

18. Degen JW, Gagnon GJ, Voyadzis JM, McRae DA, Lunsden M, Dieterich S, Molzahn I, Henderson FC: CyberKnife stereotactic radiosurgical treatment of spinal tumors for pain control and quality of life. J Neurosurg Spine 2005, 2:540-549

19. Schweikard A, Shiomi H, Adler J: Respiration tracking in radiosurgery. Med Phys 2004, 31:2738-2741.

20. Collins BT, Erickson K, Reichner CA, Collins SP, Gagnon GJ, Dieterich S, McRae DA, Zhang Y, Yousefi S, Levy E, et al: Radical stereotactic radiosurgery with real-time tumor motion tracking in the treatment of small peripheral lung tumors. Radiat Oncol 2007, 2:39.

21. Reichner C, Collins B, Gagnon G, Shakun M, Jamis-Dow C, Anderson E: The Placement of Gold Fiducials for CyberKnife Stereotactic Radiosurgery Using a Modified Transbronchial Needle Aspiration Technique. J Bronchology 2005, 12:193-195.

22. Therasse P, Arbuck SG, Eisenhauer EA, Wanders J, Kaplan RS, Rubinstein L, Verweij J, Van Glabbeke M, van Oosterom AT, Christian MC, Gwyther SG: New guidelines to evaluate the response to treatment in solid tumors. European Organization for Research and Treatment of Cancer, National Cancer Institute of the United States, National Cancer Institute of Canada. J Natl Cancer Inst 2000, 92:205-216.

23. Program CTE: Common Terminology Criteria for Adverse Events, Version 3.0. 2006, DCTD, NCl, NIH, DHHS.

24. Papiez L, Timmerman R, DesRosiers C, Randall M: Extracranial stereotactic radioablation: physical principles. Acta Oncol 2003, 42:882-894.

25. Simpson JR, Francis ME, Perez-Tamayo R, Marks RD, Rao DV: Palliative radiotherapy for inoperable carcinoma of the lung: final report of a RTOG multi-institutional trial. Int I Radiat Oncol Biol Phys 1985, 11:751-758.

doi:10.1186/1756-8722-3-39

Cite this article as: Unger et al:: Cyberknife for hilar lung tumors: report of clinical response and toxicity. Journal of Hematology \& Oncology 2010 3:39.

\section{Submit your next manuscript to BioMed Central and take full advantage of:}

- Convenient online submission

- Thorough peer review

- No space constraints or color figure charges

- Immediate publication on acceptance

- Inclusion in PubMed, CAS, Scopus and Google Scholar

- Research which is freely available for redistribution 